\title{
Food expenditure patterns in the Canadian Arctic show cause for concern for obesity and chronic disease
}

\author{
Mohammadreza Pakseresht ${ }^{1}$, Rosalyn Lang ${ }^{2}$, Stacey Rittmueller ${ }^{1}$, Cindy Roache ${ }^{1}$, Tony Sheehy ${ }^{3}$, Malek Batal ${ }^{4}$, \\ Andre Corriveau ${ }^{5}$ and Sangita Sharma ${ }^{1,6^{*}}$
}

\begin{abstract}
Background: Little is understood about the economic factors that have influenced the nutrition transition from traditional to store-bought foods that are typically high in fat and sugar amongst people living in the Canadian Arctic. This study aims to determine the pattern of household food expenditure in the Canadian Arctic.

Method: Local food prices were collected over 12 months in six communities in Nunavut and the Northwest Territories. Dietary intake data were collected from 441 adults using a validated quantitative food frequency questionnaire. Money spent on six food groups was calculated along with the cost of energy and selected nutrients per person.

Results: Participants spent approximately $10 \%$ of total food expenditure on each of the food groups of fruit/ vegetables, grains and potatoes, and dairy, 17\% on traditional meats (e.g. caribou, goose, char, and seal liver), and $20 \%$ on non-traditional meats (e.g. beef, pork, chicken, fish, and processed meats). Non-nutrient-dense foods (NNDF) accounted for $34 \%$ of food expenditure. Younger participants ( $<30$ years) spent more on NNDF and less on traditional meats compared with the older age groups. Participants with higher levels of formal education spent more on fruit and vegetables and less on traditional meats, when compared with participants with lower levels of formal education.

Conclusions: Participants spent most household income on NNDF, a possible consequence of generation discrepancy between younger and older participants. The tendency toward NNDF, particularly among youth, should be addressed with an assessment of predictive factors and the development of targeted approaches to population-based interventions.
\end{abstract}

\section{Introduction}

Between 2000 and 2004, the average mortality rates due to cardiovascular disease (CVD) in Nunavut (NU) and the Northwest Territories (NWT) were higher than the national average [1]. A cancer statistics report for the period of 2003 and 2007 shows that the annual cancer incidence rate was higher in these two territories compared to the national rate [2]. For a period of 10 years

\footnotetext{
*Correspondence: gita.sharma@ualberta.ca

'Aboriginal and Global Health Research Group, Department of Medicine, University of Alberta, 5-10 University Terrace, Edmonton, AB T6G 2 T4, Canada

${ }^{6}$ Present address: Aboriginal and Global Health Research Group, Department of Medicine, University of Alberta, 5-10 University Terrace, Edmonton, AB T6G $2 \mathrm{~T} 4$, Canada

Full list of author information is available at the end of the article
}

(1991-2000) the age-standardized incidence rate of cancer increased by $11 \%$ in the NWT and $29 \%$ in NU [3]. The crude prevalence rates of diagnosed diabetes among the population $\geq 20$ years in NU and the NWT were lower than the Canadian average [1]. This lower rate could be partially related to an under diagnosis of patients with diabetes. However, the prevalence of diabetes in the NWT increased from $1.8 \%$ to $4.6 \%$ between 1994 and 2010 . This rate increased from $1.9 \%$ to $3.3 \%$ in NU between 2000 and 2010 [3]. In 2011, the age-standardized percentage of obesity, an intermediate risk factor for chronic disease, in the NWT and NU was higher than the national average (26 and 28 vs. 18, respectively) [4].

Aboriginal populations in the Canadian Arctic are experiencing an on-going nutrition transition characterized 
by decreased traditional food intake and increased reliance on store-bought foods, high in fat, sugar, and energy, which are known for their association with developing chronic diseases and obesity [5]. In the remote and isolated communities of the Canadian Arctic, the cost of purchasing nutritious foods for a household can pose a significant barrier to achieving a healthier diet. Studies have shown that when cost is the main factor in food selection, diets tend to be nutrient-poor and energy-rich [6]. Cost of all essential household goods, including non-food items, should be considered in the context of current dietary and household patterns in order to design an effective, relevant, and culturally appropriate comprehensive program.

Analysis of the food expenditure patterns can provide insight into possible causes of obesity, as a common risk factor for chronic disease. Health providers and policy makers will benefit from this information to provide health advice at individual and population levels. The relationship between food expenditure and diet quality is potentially driving the magnitude and intensity of the nutrition transition in the Canadian Arctic. A greater understanding of the relationship between household food expenditure patterns and dietary habits is required to inform the development of effective nutrition interventions.

The aim of the present study was to determine patterns of expenditure on food groups amongst Inuit and Inuvialuit in the Canadian Arctic.

\section{Subjects and method Setting}

The study is based on data collected for the Healthy Foods North project [7] from six communities across two territories in the Canadian Arctic, NU and the NWT. Communities selected for participation represented varying percentages of Inuit or Inuvialuit populations in relation to overall community population and socioeconomic status. The community populations have been previously described [7]. In brief, the NU communities range in population from $800-1,500$ people, 80 $90 \%$ of whom self-identify as Inuit. The median Inuit age ranges from $20-26$ years, employment rate ranges from $40-60 \%$, and the median household income is CAD $\$ 34,000-60,000$ [8]. The three communities in the NWT range from 400-3,500 people with Inuvialuit populations ranging from $40-90 \%$. Median age of Inuvialuit in these communities ranges from $24-26$ years, employment rate is $40-65 \%$, and median household income is CAD $\$ 33,000-64,000$ [8]. Each of the six communities has two to three food stores that obtain food primarily through shipments from the south via airplane year round, via roads and/or ice roads for part of the year (NWT only), and via barge or sea lift once per year when the sea ice melts and shipping routes by sea are open. Food is also obtained, to varying degrees, by traditional means (e.g. hunting, fishing, food sharing networks).

\section{Data collection and analysis}

Adult participants ( $\geq 19$ years) who resided in the community for more than six months, excluding pregnant/ lactating women due to their different nutritional requirements and dietary habits, were recruited by random selection using the up-to-date community housing maps provided. If nobody was available in the randomly selected house after three attempts through in person contact, the next house was chosen. A random house was substituted if the eligible subject from the initially selected house declined to participate. This method ensured sampling from areas with varied proximities to food stores. One resident per household, ideally the person who was the main food shopper/preparer, was recruited. Exclusion criteria included pregnant/lactating women, due to this group's different nutritional requirements and possible changes in dietary habits. Response rates in NU communities ranged from $69-93 \%$ and 65 $85 \%$ in NWT communities.

A culturally appropriate quantitative food frequency questionnaire (QFFQ) was developed $[9,10]$ and validated $[11,12]$ for each territory separately. The two FFQs had the same structure to record the frequency of intake, portion size, and number of portions consumed in each setting, but each included a different number of food items (150 and 142 food items in the NU and NWT FFQs, respectively). The questionnaires were administered to 211 Inuit in NU and 230 Inuvialuit in the NWT. Information from Canadian food composition tables [13], locally collected recipes and the USDA National Nutrient Database for Standard Reference [14] were used to construct a food composition table specifically for each QFFQ. A record that contained energy and nutrient content per 100 grams for each food item in the QFFQ was created in the relevant food composition table. The data extracted from three datasets, including the food composition table, QFFQ and food item portion weights, were analysed.

Project staff were trained by the principal investigator (S.S.) to record grocery store prices for each food item listed in the QFFQ. Food prices were collected approximately once a month between June 2008 and November 2009 from at least two food stores in each community. The prices of one to five brands of each food item were recorded, based on store availability, to capture a range of prices. The average prices of different brands were considered for further analysis. The weight (grams) and price in CAD\$ of all food items were recorded per package. Data on costs for traditional meats were obtained from local hunters through the Hunters and Trappers Organization and accounted for the cost of equipment 
and supplies. All food items in the QFFQ were categorized into six main food groups [fruit and vegetables, grains and potatoes, dairy, traditional meats, nontraditional meats, and non-nutrient-dense foods (NNDF)] based on a strategy developed for previous publications for this study $[15,16]$ (Table 1). Food items in the NNDF category included all foods that did not fall into other food groups and supplied less than $5 \%$ of the reference daily intakes per serving for protein, calcium, iron, and vitamins A, C, $B_{1}, B_{2}$, and niacin [17].

A supplementary questionnaire was used to collect information regarding sex, age, weight, height, smoking status, level of education, and the Material Style of Life (MSL) scale. As a proxy for socioeconomic status, the MSL scale assessed whether a participant's household owned a series of 20 items of varying costs in working condition (e.g. television, snowmobile) [18].

Institutional Review Board approval was obtained from the Committee on Human Studies at the University of Hawaii and the Office of Human Research Ethics at the University of North Carolina at Chapel Hill. The Ethics Committee of the Beaufort Delta Health and Social Services Authority also approved this project and the Aurora Research Institute in the NWT and the Nunavut Research Institute in $\mathrm{NU}$ provided research licences.

\section{Data analysis}

Energy cost for each food group was described as the total cost spent on food items belonging to a food group to obtain optimal energy intake. Average daily consumption of each food item and the amount spent per food item per day was computed for each participant. For each FFQ item, total cost per 100 grams of each food item was calculated by dividing the average of the item's price over a 12 month period by the final unit weight (grams) and multiplying by 100 .

Only formal levels of education were recorded during data collection and the valuable traditional culture knowledge and education was not considered in the study. Level of education was categorized into low (none or some elementary school, completed elementary school or some junior high school), intermediate (completed junior high school, some high school or completed high school), and high (some college, trade school or some university or university completed). The MSL scale was also categorized into low (0-7), intermediate (8-12), and high (13-20).

Data were analyzed using STATA, version 11 (StataCorp LP, College Station, Texas, USA). Student $t$-test and chisquared test or one-way ANOVA were used to examine null hypotheses. To reduce the chances of obtaining falsepositive results (type I errors) by performing multiple pair wise tests on the study data, all $P$-values were considered statistically significant at $\alpha<0.01$.

\section{Findings}

The study sample included 441 participants $(80 \%$ of whom were women). One hundred and twenty six (29\%) participants were $\geq 50$ years and 77 (17\%) participants were under 30 years of age; the mean age was 43 (SD 14) years. Twenty three percent of participants were overweight, $47 \%$ were obese, and $71 \%$ were smokers. Overall, participants spent an average of $C A D \$ 7,217$ per year (CAD\$19.7 per day) on food. Men, participants under 30 years, participants with an intermediate level of education, and those who smoked spent significantly more on foods compared with other subgroups (Table 2).

Participants spent the most money on NNDF (CAD $\$ 2,439$ ) followed by non-traditional meats (CAD $\$ 1,422$ ) and traditional meats (CAD\$1,212) $(33.8 \%, 19.7 \%$, and $16.8 \%$ of food expenditure, respectively) (Figure 1 \& Table 3). Less than CAD $\$ 800$ per year was spent on fruit and vegetables, grains and potatoes, or dairy $(10.3 \%$, $10.3 \%$, and $9.1 \%$ of food expenditure, respectively). Men, compared with women, spent more on non-traditional meats $(24.8 \%$ vs. $18.5 \%$ of their food expenditure, $\mathrm{p}<$ 0.001 ). Participants $\geq 50$ spent more on traditional meats compared with the younger groups $(21.3 \%$ vs. $10.8 \%$ and $16.3 \%, \mathrm{p}<0.001$ ), but younger individuals tended to pay more for NNDF $(41.0 \%$ vs. $33.9 \%$ and $29.2 \%, \mathrm{p}<0.001)$. Participants who were categorized with a higher level of formal education spent more on fruit and vegetables $(12.8 \%$ vs. $9.4 \%$ and $9.6 \%, \mathrm{p}=0.004)$ but less on traditional meats $(13.7 \%$ vs. $21.3 \%$ and $14.2 \%, \mathrm{p}<0.001)$ compared with other participants.

Table 1 Food groups, subgroups and number and example of food items in each group

\begin{tabular}{lll}
\hline Food groups & Food items ( $\mathbf{n})$ & Food subgroups (food items example) \\
\hline Dairy & 11 & Milks, cheeses, yogurts, eggs \\
Grains \& potatoes & 16 & White breads, whole wheat, cereals, noodles, rice, potatoes, crisps \\
Fruit \& vegetables & 21 & Fresh fruits, packaged fruits, vegetables \\
Non-traditional meats & 26 & Beef/pork, chicken/turkey, canned fish, soups/stews \\
Traditional meats (only meats and animal organs) & 39 & $\begin{array}{l}\text { Land (caribou, muskox, polar bear), sea (seal, muktuk, char), sky } \\
\text { (goose, ptarmigan) }\end{array}$ \\
Non-nutrient-dense foods & 26 & $\begin{array}{l}\text { High fat/high sugar foods (butter, pizza, popcorn, juice sweetened, } \\
\text { ice cream, chocolates) }\end{array}$ \\
\hline
\end{tabular}


Table 2 Demographic information and annual expenditure on foods ${ }^{\dagger}$ for Inuit and Inuvialuit populations

\begin{tabular}{|c|c|c|c|}
\hline & n (\%) & CAD\$/yr & $P$ value \\
\hline & & Mean $(95 \% \mathrm{Cl})$ & \\
\hline All participants & $441(100)$ & $7217(6845,7586)$ & \\
\hline \multicolumn{4}{|l|}{ Sex } \\
\hline Men & $87(20)$ & $8483(7558,9407)$ & \multirow[t]{2}{*}{$<0.001^{¥}$} \\
\hline Women & $354(80)$ & $6904(6506,7301)$ & \\
\hline \multicolumn{4}{|l|}{ Age groups } \\
\hline$<30 y$ & $77(17)$ & 8907 (7880, 9934) & \multirow[t]{3}{*}{$<0.001^{\S}$} \\
\hline $30-49 y$ & $238(54)$ & $7666(7178,8155)$ & \\
\hline$\geq 50 y$ & $126(29)$ & $5329(4792,5866)$ & \\
\hline \multicolumn{4}{|l|}{ Education } \\
\hline Low & $159(37)$ & $6275(5771,6779)$ & \multirow[t]{3}{*}{$<0.001^{\S}$} \\
\hline Intermediate & $184(42)$ & $7877(7257,8497)$ & \\
\hline High & $89(21)$ & $7517(6619,8414)$ & \\
\hline \multicolumn{4}{|l|}{ BMI $\left(\mathrm{kg} / \mathrm{m}^{2}\right)$} \\
\hline$<25$ & $118(30)$ & $7288(6603,7960)$ & \multirow[t]{3}{*}{$0.12^{\S}$} \\
\hline $25-<30$ & $90(23)$ & $7846(6923,8769)$ & \\
\hline$\geq 30$ & $189(47)$ & $6834(6300,7368)$ & \\
\hline \multicolumn{4}{|l|}{ Smoking } \\
\hline No & $127(29)$ & $5769(5171,6367)$ & \multirow[t]{2}{*}{$<0.001^{*}$} \\
\hline Yes & $314(71)$ & $7766(7315,8217)$ & \\
\hline \multicolumn{4}{|l|}{ MSL score ${ }^{\ddagger}$} \\
\hline Low & $127(29)$ & $7306(6587,8024)$ & \multirow[t]{3}{*}{$0.42^{\S}$} \\
\hline Intermediate & $151(35)$ & $6875(6317,7433)$ & \\
\hline High & $155(36)$ & $7455(6772,8137)$ & \\
\hline
\end{tabular}

${ }^{\dagger}$ Overall food expenditure for six main food groups: fruit \& vegetables, grains \& potatoes, dairy, traditional meats, non-traditional meats, and non-nutrient-dense foods.

FLow: 0-7, Intermediate: 8-12, High: 13-20.

${ }^{*} P$ value for Student $t$-test for food expenditure.

${ }^{S} P$ value for One way ANOVA for food expenditure. MSL: Material Style of Life.

No statistically significant difference was observed for food group expenditure amongst participants in various BMI, MSL score, and smoking categories.

\section{Interpretation}

To the best of our knowledge, this is the first study to examine food expenditure patterns in two territories in the Canadian Arctic (NU and the NWT). About 34\% of total food expenditure by participants was spent on NNDF. Participants also spent more money on nontraditional meats and traditional meats, compared with fruit and vegetables, grains and potatoes, and dairy products.

The findings of the present study raise significant questions concerning the disproportionate amount of money being spent on NNDF, which do not provide adequate nutrition, but provide relatively high levels of energy. NNDF includes a relatively large group of items that were usually available in community food stores, in contrast to fresh produce, which was not as readily available on a consistent basis. This suggests that, on a daily basis, most of the NNDF items were more available than fresh produce. For individuals who are food shopping for the entire family, the purchase of NNDF may be the easiest way of obtaining the most energy while ensuring that all members of the family were satisfied. In addition, a taste preference may exist for high fat foods [19]. Drewnowski and Specter [20] reported that the relationship between obesity and poverty can be explained by the low cost of foods that are energy dense and the taste and acceptability of these foods that are usually high in fat and sugar. Affordability, quality of store-bought perishable foods, exposure to fresh produce, and culinary knowledge are other factors that could be linked to lower expenditure on nutrient-dense food groups, particularly fruit and vegetables. Increased cost of fuel and hunting equipment, as well as reduced availability of land, sea and sky resources, such as caribou, Arctic char, and geese, possibly as a result of climate changes [21], are potential reasons that traditional meats expenditure is lower than non-traditional meat expenditure among this population.

Food group expenditure in this study varied among age, gender, and education subgroups. This finding is supported by results from an Expenditure Survey conducted by the U.S. Bureau of Labor Statistics [22]. The reality in traditional and remote communities is that men generally spend more time outside the household for work and have less food-preparation skills than women; this could explain the gender difference of nontraditional meat food expenditure in this study. Physiological need difference between genders for protein and energy expenditure could also partly explain the variety of meat intake and expenditure between men and women in the study population [23]. The finding that women consume diets with less meat reported by other studies $[24,25]$ support our result.

Our analysis showed a statistically significant, increasing trend for traditional meats expenditure and a decreasing trend for NNDF expenditure with an increase of age. Similarly, in the study by Fan et al. [22] older households were less likely to be in the fast-fooddominant food expenditure category. Fast food tends to be more energy dense, higher in saturated fat and salt, and lower in micronutrients relative to other foods [26] and thus, could be considered equivalent to NNDF in this study. It is known that dietary habits tend to be relatively stable over time [27], suggesting that older people may have a higher tendency towards traditional meats in these communities. 


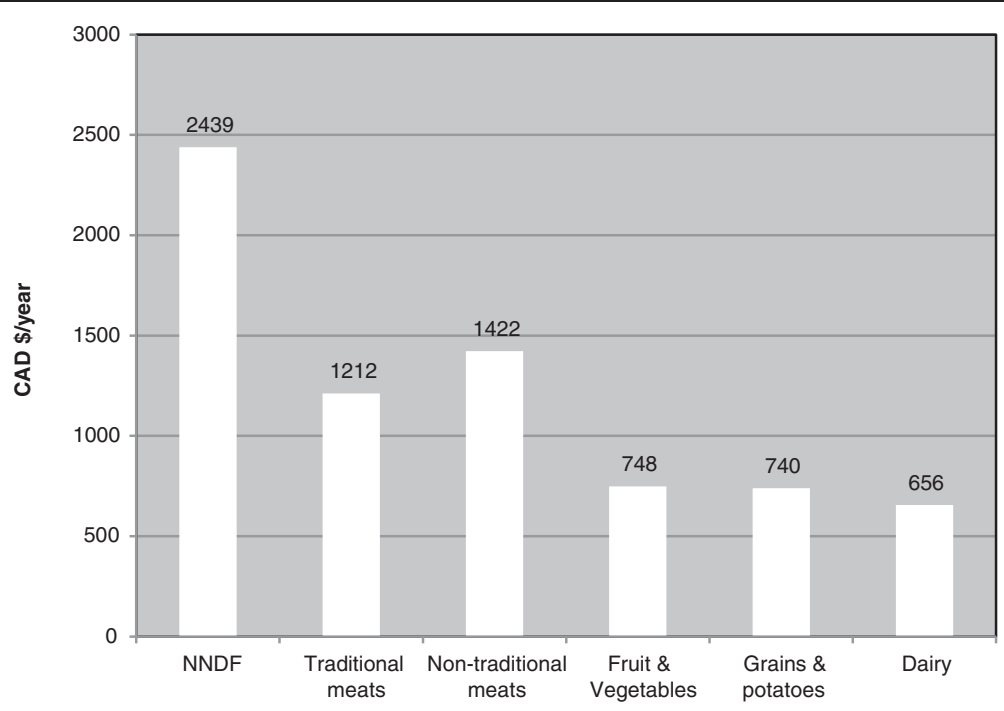

Figure 1 Average annual food expenditure (CAD\$) by Inuit and Inuvialuit for six food groups. NNDF: non-nutrient-dense foods.

The finding that participants with higher levels of formal education spent significantly more on fruit and vegetables is comparable with the results from the East Anglia cohort of the European Prospective Investigation of Cancer analysis [27]. This finding could be linked to having greater nutrition knowledge regarding fruit and vegetables, being more familiar with method of preparing dishes using fruit and vegetables, and more taste preference for this food group. A high level of expenditure on traditional meats by people classified with a lower level of formal education is compatible with the similar expenditure pattern and amount among older participants (both groups spent $21 \%$ of the food expenditure on traditional meats). This indicates a preference towards traditional meats is likely related to interest in and commitment to customs as well as an awareness of nutritional values of traditional meats.

In 2007-2008, approximately $7.7 \%$ of Canadian households and 21\% of off-reserve Aboriginal households were food insecure [28]. In one recent survey, nearly $70 \%$ of Inuit families in $16 \mathrm{NU}$ communities were food insecure [29]. Previous studies among this population indicate that this may be an issue among Inuit and Inuvialuit [7]. In other populations, individuals who are food insecure and have a low income often rely heavily on low-cost foods that are high in energy (sugar and fat) but lack essential nutrients $[20,30]$. In this study, however, no difference in patterns of food expenditure was found between different levels of socioeconomic status (MSL scale), suggesting factors such as taste preference or availability may have more of an influence on food expenditure patterns, at least among people with adequate income. In addition, this finding indicates that any future intervention program could be broadly applied to all members of the community.

Nutrition related diseases such as obesity and diet related anemia can be caused by an insufficient intake of food, insufficient intake of certain nutrients or by an over consumption of certain foods [31]. Addressing dietary inadequacies through appropriate and relevant intervention programming has the potential to positively impact health status and to reduce the cost to health systems in the Canadian Arctic.

Municipal, regional, territorial, and federal governments and organizations should consider the findings of this study in the development, design, and implementation of any programming or subsidies related to the food environment in the Canadian Arctic. Particular focus should be given to costs associated with hunting and gathering and supportive programs for younger generations of Inuit/Inuvialuit to learn hunting and gathering skills.

All future programming should consider challenges to obtaining a healthy diet in the Canadian Arctic, whether they relate to store-bought or traditional meats. High costs associated with household essentials, such as diapers and toilet paper, can take away from the disposable household income available for the purchase of food. As such, given the importance of traditional meats to the diet of Inuit/Inuvialuit, subsidies should be provided to reduce costs associated with hunting, such as snowmobile parts, ammunition, and fishing supplies. Any programs or subsidies should include rigorous community consultation to ensure programs are relevant and appropriate for the current Northern environment. Communities that are to receive the program and/or subsidy should endorse all promoted items. 
Table 3 Proportion of food expenditure for food groups based on demographic variable categories

\begin{tabular}{|c|c|c|c|c|c|c|}
\hline & $\begin{array}{c}\text { Fruit \& vegetables \% } \\
(95 \% \mathrm{Cl})\end{array}$ & $\begin{array}{c}\text { Grains \& potatoes \% } \\
(95 \% \mathrm{Cl})\end{array}$ & $\begin{array}{l}\text { Dairy \% } \\
(95 \% \mathrm{Cl})\end{array}$ & $\begin{array}{c}\text { Non-traditional meats \% } \\
(95 \% \mathrm{Cl})\end{array}$ & $\begin{array}{c}\text { Traditional meats \% } \\
(95 \% \mathrm{Cl})\end{array}$ & $\begin{array}{l}\text { NNDF \% } \\
(95 \% \mathrm{Cl})\end{array}$ \\
\hline All participants & $10.3(9.5,11.0)$ & $10.3(9.9,10.8)$ & $9.1(8.3,9.8)$ & $19.7(18.7,20.8)$ & $16.8(15.5,18.1)$ & $33.8(32.3,35.3)$ \\
\hline \multicolumn{7}{|l|}{ Sex } \\
\hline Men & $8(6.8,10.4)$ & $9(8.9,10.8)$ & $8(6.8,9.4)$ & $24(22.2,27.4)$ & $13.6(10.9,16.3)$ & $35.0(31.6,38.4)$ \\
\hline Women & $10.6(9.8,11.5)$ & $10.5(10.0,11.0)$ & $9.3(8.4,10.2)$ & $18.5(17.4,19.6)$ & $17.5(16.1,19.0)$ & $33.5(31.8,35.2)$ \\
\hline$P$ value ${ }^{\dagger}$ & 0.03 & 0.27 & 0.21 & $<0.001$ & 0.02 & 0.44 \\
\hline \multicolumn{7}{|l|}{ Age groups } \\
\hline$<30 y$ & $8.2(6.4,10.0)$ & $9.4(8.3,10.5)$ & $10.7(8.4,12.9)$ & $20.0(17.3,22.6)$ & $10.8(8.2,13.4)$ & $41.0(36.8,45.1)$ \\
\hline $30-49$ y & $10.5(9.4,11.5)$ & $10.4(9.7,11.0)$ & $8.5(7.6,9.4)$ & $20.4(19.0,21.8)$ & $16.3(14.7,17.9)$ & $33.9(32.0,35.8)$ \\
\hline$\geq 50 y$ & $11.0(9.6,12.5)$ & $11.0(10.2,11.9)$ & $9.2(7.7,10.7)$ & $18.3(16.4,20.2)$ & $21.3(18.5,24.0)$ & $29.2(26.4,31.9)$ \\
\hline$P$ value ${ }^{\ddagger}$ & 0.04 & 0.08 & 0.11 & 0.23 & $<0.001$ & $<0.001$ \\
\hline \multicolumn{7}{|l|}{ Education } \\
\hline Low & $9.4(8.4,10.5)$ & $10.7(9.9,11.6)$ & $8.1(7.0,9.2)$ & $18.7(17.0,20.5)$ & $21.3(19.0,23.6)$ & $31.7(29.2,34.1)$ \\
\hline Intermediate & $9.6(8.6,10.7)$ & $10.2(9.5,10.9)$ & $9.9(8.6,11.2)$ & $19.7(18.1,21.2)$ & $14.2(12.3,16.0)$ & $36.3(33.9,38.8)$ \\
\hline High & $12.8(10.5,15.1)$ & $9.8(8.9,10.7)$ & $8.8(7.2,10.4)$ & $21.5(18.9,24.1)$ & $13.7(11.2,16.2)$ & $33.5(30.2,36.7)$ \\
\hline$P$ value $^{\ddagger}$ & 0.004 & 0.33 & 0.11 & 0.18 & $<0.001$ & 0.03 \\
\hline \multicolumn{7}{|l|}{ BMI $\left(\mathrm{kg} / \mathrm{m}^{2}\right)$} \\
\hline$<25$ & $9.0(7.9,10.2)$ & $115(10.5,12.6)$ & $10.0(8.2,11.9)$ & $18.6(16.7,20.4)$ & $15.9(13.4,18.3)$ & $34.9(32.0,37.9)$ \\
\hline $25-<30$ & $9.5(8.1,11.0)$ & $9.9(9.0,10.9)$ & $8.2(6.9,9.6)$ & $20.4(18.0,22.8)$ & $16.1(13.3,18.9)$ & $35.8(32.4,39.2)$ \\
\hline$\geq 30$ & $11.9(10.5,13.3)$ & $10.1(9.5,10.7)$ & $8.7(7.7,9.8)$ & $19.7(18.1,21.4)$ & $17.9(15.9,19.9)$ & $31.6(29.3,33.9)$ \\
\hline$P$ value & 0.01 & 0.02 & 0.23 & 0.48 & 0.37 & 0.07 \\
\hline \multicolumn{7}{|l|}{ Smoking } \\
\hline No & $11.0(9.7,12.3)$ & $10.7(9.9,11.6)$ & $8.6(7.2,9.9)$ & $18.5(16.7,20.2)$ & $18.8(16.3,21.3)$ & 32. $(29.6,35.2)$ \\
\hline Yes & $10.0(9.0,10.9)$ & $10.2(9.6,10.8)$ & $9.3(8.4,10.2)$ & $20.3(19.0,21.6)$ & $15.8(14.3,17.3)$ & $34.4(32.6,36.2)$ \\
\hline$P$ value $^{\dagger}$ & 0.25 & 0.29 & 0.40 & 0.11 & 0.04 & 0.25 \\
\hline \multicolumn{7}{|l|}{ MSL score ${ }^{¥}$} \\
\hline Low & $8.6(7.4,9.8)$ & $10.6(9.6,11.6)$ & $10.2(8.5,11.9)$ & $20.1(18.0,22.2)$ & $15.0(12.8,17.2)$ & $35.4(32.3,38.6)$ \\
\hline Intermediate & $11.0(9.5,12.6)$ & $10.3(9.5,11.1)$ & $9.0(7.7,10.3)$ & $20.9(19.1,22.8)$ & $16.0(13.6,18.3)$ & $32.7(30.3,35.2)$ \\
\hline High & $10.7(9.5,11.9)$ & $10.1(9.4,10.9)$ & $8.0(7.0,9.1)$ & $18.3(16.7,19.8)$ & $18.9(16.7,21.0)$ & $34.0(31.5,36.5)$ \\
\hline$P$ value $^{\ddagger}$ & 0.03 & 0.75 & 0.08 & 0.10 & 0.04 & 0.38 \\
\hline
\end{tabular}

${ }^{\dagger} P$ value for Student $t$-test.

${ }^{\ddagger} P$ value for One way ANOVA.

${ }^{¥}$ Low: 0-7, Intermediate: 8-12, High: 13-20.

MSL: Material Style of Life.

NNDF: non-nutrient-dense foods.

Considering the findings of this study in relation to food choices and costs, programs should be developed to promote food items that have the largest impact on diet and be the most amenable to Inuit/Inuvialuit communities, such as eggs and yogurt. In addition, the current study shows that younger people tended to pay more for NNDF. Thus, particular emphasis should be paid to engaging young people in the development and implementation of household and individual budgeting support, in addition to healthy food choices, as a key element of any intervention program.
Further research into all factors impacting overall household income in the Canadian Arctic is required to ensure any program and policy decisions are appropriate, relevant, and timely. If a large percentage of household income is spent on NNDFs, then the available disposable income will decrease, considering a subsidy of only healthy food choices. Without community-led programs that support healthy food choices, simply subsidizing the cost of certain foods will continue to increase the likelihood of food insecurity in the Canadian Arctic. 
Food prices were sampled over a 12-month period and therefore, variations in food costs due to seasonality and for different brands were captured. In addition, there was very limited diversity for food item brands between communities due to remoteness. Women contributed more than men in the study because the study preference was to recruit a member of each household who was the main person shopping for and preparing food for the family. This might limit the ability to generalize the findings to people living outside of these communities. However, it was necessary to collect detailed and accurate dietary information from participants to address the HFN project's objectives. This need could be addressed by recruiting main food shoppers from each household as those people were more likely to have food knowledge and manage food expenditure for the household. Accordingly, collecting more accurate dietary data was more advantageous to the study compared with the disadvantage associated with potential biases. Majority (54\%) of participants were between 30 and 49 years. This matches with the age pyramid in these communities where $46 \%$ of the population in the six communities was also between 30 and 49 years. A chi-squared test also did not show any significant difference between communities and the study participants for the proportion of people in the three age groups $(P=0.19)$. However, women usually attach greater importance to healthy eating (e.g. more fibre and less fat intake) [32]. Only formal levels of education were recorded during data collection because the valuable traditional culture knowledge and education was not easily measurable.

\section{Conclusion}

High expenditure on NNDF is the main finding of this study. Predictive factors of high expenditure on NNDF and opportunities for reduced spending on NNDF and barriers for increased spending on traditional meats should be understood before any intervention to improve dietary situation in this population. Educational efforts regarding healthy eating choices should focus on younger age groups. In addition, improvement in household income, reduction in cost of hunting and fishing, and availability of traditional meats (i.e. declining herds) would support any healthy eating intervention program in Canadian Arctic.

\section{Competing interests}

The authors declare that they have no competing interests.

\section{Authors' contributions}

MP did data analysis, data interpretation, literature search, and wrote the article. RL and SR collected the data, reviewed literature and drafted the initial version of the article. CR, TS, MB and AC contributed in data interpretation and writing the article. SS designed the study and was principal investigator of the project. She supervised all stages of the project and writing this article. All authors read and approved the final manuscript.

\section{Acknowledgements}

We are grateful to our project participants, community staff, Aurora Research Institute, the Government of Nunavut, the Government of the Northwest Territories, and Health Canada.

\section{Funding source}

American Diabetes Association, Government of the Northwest Territories, and Government of Nunavut.

\section{Author details}

${ }^{1}$ Aboriginal and Global Health Research Group, Department of Medicine, University of Alberta, 5-10 University Terrace, Edmonton, AB T6G 2 T4, Canada. ${ }^{2}$ North Carolina A\&T State University, Department of Biology, African Americans \& Alzheimer's Disease Research Study, 2105 Yanceyville Building, Greensboro, NC 27410, USA. ${ }^{3}$ School of Food and Nutritional Sciences, University College Cork, Cork, Ireland. ${ }^{4}$ Département de nutrition, Faculté de medicine, Université de Montréal, C.P. 6128, Succursale Centre-ville, Montréal, Québec H3C 3 J7, Canada. ${ }^{5}$ The Northwest Territories Department of Health and Social Services, Yellowknife, NT X1A 2 L9, Canada. ${ }^{6}$ resent address: Aboriginal and Global Health Research Group, Department of Medicine, University of Alberta, 5-10 University Terrace, Edmonton, AB T6G 2 T4, Canada.

Received: 7 November 2013 Accepted: 9 April 2014

Published: 17 April 2014

\section{References}

1. Public Health Agency of Canada: Tracking Heart Disease and Stroke in Canada. 2009. http://www.phac-aspc.gc.ca/publicat/2009/cvd-avc/index-eng.php.

2. Provincial Cancer Profiles. Dynamic views of cancer statistics for prioritizing cancer. 2014. http://cancerprofiles.ca/en/incidencerates/index.php? cancer $=001$ \&age $=001 \&$ se $=0$ \&year $=0$ \&race $=00$ \& province $=00 \&$ type $=$ incd\&sortVariableName=rate\&sortOrder=default.

3. Public Health Agency of Canada: Chronic Disease Infobase. 2013. http://66.240.150.17/cubes/intro-e.html.

4. Employment and Social Development Canada: Indicators of well-being in Canada, Health-Obesity. 2014. http.//www4.hrsdc.gc.ca/.3ndic.1t.4r@-eng.jsp?iid=6.

5. Kuhnlein HV, Receveur O, Soueida R, Egeland GM: Arctic indigenous peoples experience the nutrition transition with changing dietary patterns and obesity. J Nutr 2004, 134(6):1447-1453.

6. Darmon $N$, Ferguson $E$, Briend A: Do economic constraints encourage the selection of energy dense diets? Appetite 2003, 41(3):315-322.

7. Sharma S: Assessing diet and lifestyle in the Canadian Arctic Inuit and Inuvialuit to inform a nutrition and physical activity intervention programme. J Hum Nutr Diet 2010, 23(Suppl 1):5-17.

8. Statistics Canada: 2006 Aboriginal population profile. 2006. http://www12 statcan.gc.ca/census-recensement/2006/dp-pd/prof/92-594/.

9. Sharma S, De Roose E, Cao X, Pokiak A, Gittelsohn J, Corriveau A: Dietary intake in a population undergoing a rapid transition in diet and lifestyle: the Inuvialuit in the Northwest Territories of Arctic Canada. Can J Public Health 2009, 100(6):442-448,

10. Sharma S, Cao X, Roache C, Buchan A, Reid R, Gittelsohn J: Assessing dietary intake in a population undergoing a rapid transition in diet and lifestyle: the Arctic Inuit in Nunavut, Canada. Br J Nutr 2010, 103(5):749-759.

11. Pakseresht M, Sharma S: Validation of a quantitative food frequency questionnaire for Inuit population in Nunavut, Canada. J Hum Nutr Diet 2010, 23(Suppl 1):67-74.

12. Pakseresht M, Sharma S: Validation of a culturally appropriate quantitative food frequency questionnaire for Inuvialuit population in the Northwest Territories, Canada. J Hum Nutr Diet 2010, 23(Suppl 1):75-82.

13. Health Canada: Canadian Nutrient File (CNF) 2010. 2013. http://www.hc-sc.gc.ca/ fn-an/nutrition/fiche-nutri-data/cnf_downloads-telechargement_fcen-eng.php.

14. United States Department of Agriculture: Dietary Guidelines. 2010. https://fnic.nal.usda.gov/dietary-guidance/dietary-guidelines.

15. Erber E, Beck L, Hopping BN, Sheehy T, De Roose E, Sharma S: Food patterns and socioeconomic indicators of food consumption amongst Inuvialuit in the Canadian Arctic. J Hum Nutr Diet 2010, 23(Suppl 1):59-66.

16. Hopping BN, Erber E, Mead E, Sheehy T, Roache C, Sharma S: Socioeconomic indicators and frequency of traditional food, junk food, and fruit and vegetable consumption amongst Inuit adults in the Canadian Arctic. J Hum Nutr Diet 2010, 23(Suppl 1):51-58. 
17. Drewnowski A: Concept of a nutritious food: toward a nutrient density score. Am J Clin Nutr 2005, 82(4):721-732.

18. Gittelsohn J, Anliker JA, Sharma S, Vastine AE, Caballero B, Ethelbah B: Psychosocial determinants of food purchasing and preparation in American Indian households. J Nutr Educ Behav 2006, 38(3):163-168.

19. Drewnowski A, Almiron-Roig E: Human Perceptions and Preferences for Fat-Rich Foods. In Fat Detection: Taste, Texture, and Post Ingestive Effects. Edited by Montmayeur JP ICJ. Boca Raton (FL): CRC Press; 2010.

20. Drewnowski A, Specter SE: Poverty and obesity: the role of energy density and energy costs. Am J Clin Nutr 2004, 79(1):6-16.

21. World Wild life Fund: Effects of Climate Change on Arctic Migratory Birds. 2012. http://awsassets.panda.org/downloads/arctic_birds_factsheet.pdf.

22. Fan JX, Brown BB, Kowaleski-Jones L, Smith KR, Zick CD: Household food expenditure patterns: a cluster analysis. Monthly Labor Rev 2007, 130:38-51.

23. Adams CJ: Sexual Politics of Meat: A Feminist-Vegetarian Critical. Cambridge: Polity Press; 1990

24. Wirfalt AK, Jeffery RW: Using cluster analysis to examine dietary patterns: nutrient intakes, gender, and weight status differ across food pattern clusters. J Am Diet Assoc 1997, 97(3):272-279.

25. Shi L: Sociodemographic characteristics and individual health behaviors. South Med J 1998, 91(10):933-941.

26. Pereira MA, Kartashov Al, Ebbeling CB, Van HL, Slattery ML, Jacobs DR Jr, Ludwig DS: Fast-food habits, weight gain, and insulin resistance (the CARDIA study): 15-year prospective analysis. Lancet 2005, 365(9453):36-42.

27. Fraser GE, Welch A, Luben R, Bingham SA, Day NE: The effect of age, sex, and education on food consumption of a middle-aged English cohortEPIC in East Anglia. Prev Med 2000, 30(1):26-34.

28. Health Canada: Household Food Insecurity in Canada in 2007-2008: Key Statistics and Graphics. 2012. http://www.hc-sc.gc.ca/fn-an/surveill/nutrition/ commun/insecurit/key-stats-cles-2007-2008-eng.php.

29. Egeland GM, Pacey A, Cao Z, Sobol I: Food insecurity among Inuit preschoolers: Nunavut Inuit Child Health Survey, 2007-2008. CMAJ 2010, 182(3):243-248.

30. Lambden J, Receveur O, Marshall J, Kuhnlein HV: Traditional and market food access in Arctic Canada is affected by economic factors. Int $J$ Circumpolar Health 2006, 65(4):331-340.

31. WHO: Integrating Poverty and Gender Into Health Programmes: A Sourcebook for Health Professionals. 2010. http://www.wpro.who.int/publications/ PUB_978_929061_245_2/en/index.html.

32. Davy SR, Benes BA, Driskell JA: Sex differences in dieting trends, eating habits, and nutrition beliefs of a group of midwestern college students. J Am Diet Assoc 2006, 106(10):1673-1677.

doi:10.1186/1479-5868-11-51

Cite this article as: Pakseresht et al:: Food expenditure patterns in the Canadian Arctic show cause for concern for obesity and chronic disease. International Journal of Behavioral Nutrition and Physical Activity 2014 11:51.

\section{Submit your next manuscript to BioMed Central and take full advantage of:}

- Convenient online submission

- Thorough peer review

- No space constraints or color figure charges

- Immediate publication on acceptance

- Inclusion in PubMed, CAS, Scopus and Google Scholar

- Research which is freely available for redistribution 